\title{
Synthesis and Solid-State Polymerization of Liquid-Crystalline Acrylic Monomers Containing Chiral Epoxy Groups
}

\author{
Tadafumi SHINDO and Toshiyuki URYU* \\ Central Research Institute, Dai Nippon Printing Co., Ltd., \\ Shinjuku-ku, Tokyo 162-01, Japan \\ * Institute of Industrial Science, University of Tokyo, \\ Roppongi, Minato-ku, Tokyo 106, Japan
}

(Received September 26, 1989)

\begin{abstract}
Solid-state polymerization of liquid-crystalline monomers by low energy electron beam was examined. Six kinds of mono-functional acryloyl monomers having phenyl benzoate as mesogen were synthesized. Of them, two monomers had a chiral epoxy group as well. All polymers and monomers were studied by differential scanning calorimetry, cross-polarizing microscopy and NMR. The presence of the epoxy group stabilized liquid-crystalline phase. In spite of mono-functional acryloyl monomers, monomers containing an epoxy group gave insoluble crosslinked polymers by EB irradiation, while radical polymerization provided a soluble polymer. The solid-state $\mathrm{CP} / \mathrm{MAS}{ }^{13} \mathrm{C}$ NMR spectrum of the crosslinked polymer was similar to that of a radically-polymerized, linear polymer. DSC and crosspolarizing microscopy measurements exhibited that the crosslinked polymer had phase transition due to crystal-to-smectic, smectic-to-nematic and nematic-to-isotropic changes. The X-ray diffraction pattern showed an orientation of mesogen in EB-polymerized polymers.

KEY WORDS Electron Beam / Solid-State Polymerizarion / LiquidCrystalline Polymer / Epoxy Group /
\end{abstract}

In industrial production by curing and polymerization of resins, radiation processing has several advantage over thermal processing. Recent developments related to the radiation processing cover wide fields such as coatings, magnetic media, and adhesives. ${ }^{1}$ Radiationcurable resins often consist of acrylic-oligomers and their mixtures with reactive monomers. For radiation-polymerized oligomers, there are reports on the morphology and mechanical properties $^{2}$ and the behavior of electron-beam (EB) curing. ${ }^{3}$ We have also studied the EB polymerization of acrylic monomer-polymer systems, revealing that the obtained polymer films have good properties as pressure-sensitive adhesives. $^{4,5}$

Thermotropic liquid-crystalline polymers have been applied for producing materials for ultrahigh modulus and recording. Of these polymers, side-chain type liquid-crystalline polymers possess several advantages for the material of recording over main-chain type liquid-crystalline polymers. ${ }^{6,7}$ In addition, polymers with ferro-electric property ${ }^{8}$ and optical recording property ${ }^{9}$ have been investigated.

Previously, we reported the solid-state polymerization of acrylic oligomers ${ }^{10}$ and of liquid-crystalline monomers having mesogenic biphenyl groups and terminal acryloyl groups ${ }^{11}$ by low energy electron beam.

Thermotropic liquid-crystalline acryloyl monomers were highly ordered monomers and seem to have intermolecular interactions. Therefore, these compounds are expected to be converted from monomers to polymers in high yield in the solid-state polymerization. In addition, optically active compounds may have 
an advantage for high conversion because in such compounds the molecular conformation is more restricted than optically inactive ones.

In this paper, we wish to report the synthesis and solid-state polymerization of optically active liquid-crystalline acrylic monomers which contain a mesogenic phenyl benzoate group, a flexible spacer with an asymmetric epoxy group, and a terminal acryloyl group. The properties of the optically active monomers and the corresponding racemic monomers, and of the polymers were investigated by means of solution and solid-state ${ }^{13} \mathrm{C}$ NMR spectroscopy, differential calorimetry (DSC), and hot-stage microscopic observation.

\section{EXPERIMENTAL}

\section{(S,S)-2,3-Epoxyhexanol (1)}

The reaction is shown in Scheme 2. A (E)-2-Hexenol $(20.4 \mathrm{~g}(204 \mathrm{mmol}))$ solution in $100 \mathrm{ml}$ of methylene chloride was mixed with a mixture of $3 \mathrm{M}$ tert-butyl hydroperoxide solution in heptane $(134 \mathrm{ml})$, and of a methylene chloride solution $(240 \mathrm{ml})$ of $\mathrm{L}-(+)$ tartaric acid diethyl ester $(2.48 \mathrm{~g}(12 \mathrm{mmol}))$, titanium tetraisopropoxide $(2.84 \mathrm{~g}(10 \mathrm{mmol}))$, and powdered $4 \mathrm{~A}$ molecular sieve $(6.0 \mathrm{~g})$. The reaction was performed in a three-necked flask under nitrogen at -20 to $-15^{\circ} \mathrm{C}$ for $2.5 \mathrm{~h}$. The reaction mixture cooled at $0^{\circ} \mathrm{C}$ was slowly poured into a $200 \mathrm{ml}$ precooled aqueous solution of ferrous sulfate heptahydrate $(66 \mathrm{~g})$ and tartaric acid (20 g). The separated organic layer was treated with $40 \mathrm{ml}$ of a precooled $\left(0^{\circ} \mathrm{C}\right)$ solution of $30 \%(\mathrm{w} / \mathrm{v}) \mathrm{NaOH}$ in saturated brine. The solution was washed with $50 \mathrm{ml}$ of water and dried over sodium sulfate, filtered and concentrated. Purification by distillation (bp $97-98^{\circ} \mathrm{C} / 17 \mathrm{mmHg}$ ) gave a colorless oil.. Yield of $(S, S)$-2,3-epoxyhexanol: $3.6 \mathrm{~g}(15 \%)$. An enantiomeric excess of $88 \%$ was determined by NMR analysis with $\mathrm{Eu}(\mathrm{hfc})_{3} \cdot[\alpha]_{\mathrm{D}}^{25}-44^{\circ}(c$ $1 \%, \mathrm{CHCl}_{3}$ ). $\left(\right.$ lit. $^{13}-46.6^{\circ}$ ).
4'-Benzyloxy 4-[(S,S)-2,3-epoxyhexyloxy $]$ benzene (2)

$(S, S)$-2,3-Epoxyhexanol (3.6 g (31 mmol)) was reacted with 4-benzyloxyphenol $(6.0 \mathrm{~g}$ $(31 \mathrm{mmol}))$ and triphenylphosphine $(8.1 \mathrm{~g} \mathrm{(31}$ $\mathrm{mmol})$ ) in $100 \mathrm{ml}$ of tetrahydrofuran (THF). To the solution was dropwise added an azodicarboxylic acid diethyl ester (5.4 g (31 mmol)) solution in THF. The resulting solution was stirred at room temperature overnight. After removing the solvent, diethyl ether was added. Crude products were purified by column chromatography (silica gel; ethyl acetate-hexane (1:9) as eluent), and recrystallized from a mixture of ethyl acetate and hexane. Yield: $4.2 \mathrm{~g}$ $(47 \%)$ mp $68-69^{\circ} \mathrm{C}$. $[\alpha]_{\mathrm{D}}^{25}-14.3^{\circ}$ (c $1 \%$, $\mathrm{CHCl}_{3}$ ).

\section{4-[(S,S)-2,3-Epoxyhexyloxy] phenol (3)}

4'-Benzyloxy 4-[(S,S)-2,3-epoxyhexyloxy]benzene $(4.0 \mathrm{~g}(13.4 \mathrm{mmol}))$ which had been dissolved in dry ethyl acetate $(40 \mathrm{ml})$ was reduced with hydrogen over palladium carbon $(0.5 \mathrm{~g})$ in dry ethyl acetate $(25 \mathrm{ml})$. Crude products were purified by column chromatography (silica gel; hexane-ethyl acetate $(6: 4)$ ) and then recrystallized from a mixture of ethyl acetate and hexane. Yield: $2.6 \mathrm{~g}(93 \%) .[\alpha]_{\mathrm{D}}^{25}$ $-22.0^{\circ}\left(\mathrm{c} 1 \%, \mathrm{CHCl}_{3}\right)$.

\section{$4^{\prime}-[(S, S)$-Epoxyhexyloxy $]$ phenyl 4- $(\omega-$ Acryl- oyloxyhexyloxy)benzoate (trans-EPAB-6)}

A representative procedure is described for $4^{\prime}-[(S, S)-2,3$-epoxyhexyloxy]phenyl 4- $(\omega$-acryloyloxyhexyloxy)benzoate. 4- $(\omega$-Acrlyoyloxyhexyloxy)benzoic acid (1.7 g (5.8 mmol)), 2 drops of dimethylformamide, and a small amount of 2,6-di-tert-butylphenol were dissolved in thionyl chloride (about $5 \mathrm{ml}$ ). The solution was evaporated to dryness by means of a flash evaporator. The product was dissolved in $30 \mathrm{ml}$ of dry THF and added to solution of $3(1.2 \mathrm{~g}(5.8 \mathrm{mmol}))$ and sodium hydride $(0.2 \mathrm{~g})$ in $100 \mathrm{ml}$ of dry THF. After $4 \mathrm{~h}$ reaction, excess sodium hydride was quenched by the addition of water, and the reaction 
products were extracted with diethyl ether and dried. The crude products were purified by column chromatography (silica gel; methylene chloride), and recrystallized from a mixture of ethyl acetate and hexane. Yield: $1.0 \mathrm{~g}(34 \%)$. $[\alpha]_{\mathrm{D}}^{25}-10.8^{\circ}\left(\mathrm{c} 1 \%, \mathrm{CHCl}_{3}\right)$. Anal. Calcd. for $\mathrm{C}_{28} \mathrm{H}_{34} \mathrm{O}_{7}$ : C, 69.69\%; H, 7.12\%. Found: C, $69.68 \% ; \mathrm{H}, 7.15 \%$.

\section{$4^{\prime}-[(S, S)-2,3-$ Epoxyhexyloxy $]$ phenyl 4- $(\omega-$ Acryloyloxyundecanoxy)benzoate (trans- EPAB-11)}

The synthetic procedure was the same as that of trans-EPAB-6. 4-( $\omega$-Acryloyloxyundecanoxy)benzoic acid $(1.9 \mathrm{~g}(5.3 \mathrm{mmol}))$ was reacted with $3(1.1 \mathrm{~g}(5.3 \mathrm{mmol})$. Yield: $1.3 \mathrm{~g}$ $(50 \%) .[\alpha]_{\mathrm{D}}^{25}-8.3^{\circ}$ (c $\left.1 \%, \mathrm{CHCl}_{3}\right)$. Anal. Calcd. for $\mathrm{C}_{33} \mathrm{H}_{44} \mathrm{O}_{7}$ : C, $71.71 \% ; \mathrm{H}, 8.02 \%$. Found: $\mathrm{C}, 71.46 \%$; $\mathrm{H}, 8.11 \%$.

\section{4-(2,3-Epoxyhexyloxy)phenol (4)}

4-(2,3-Epoxyhexyloxy)phenol was synthesized in three steps, as shown in Scheme 3. First, 4'-benzyloxy 4-(2-hexenoxy)benzene 5 was prepared. 4-Benzyloxyphenol (10.0 g (50 $\mathrm{mmol}))$, 2-hexenol $(5.0 \mathrm{~g}(50 \mathrm{mmol}))$, and triphenylphosphine $(13.1 \mathrm{~g}(50 \mathrm{mmol}))$ were dissolved in $100 \mathrm{ml}$ of dry THF. To the solution was dropwise added a solution of azodicarboxylic acid diethyl ester $(8.7 \mathrm{~g}(50 \mathrm{mmol}))$ in THF. The resulting solution was stirred at room temperature overnight. After the solution was evaporated, ether was added to give white precipitates. Crude products were purified by column chromatography (silica gel; hexaneethyl acetate (9:1)), and recrystallized from a mixture of ethyl acetate and hexane. Yield of 5: $88 \mathrm{~g}(63 \%)$. mp 63-65 ${ }^{\circ} \mathrm{C}$. Next, $4^{\prime}$-benzyloxy 4-(2,3-epoxyhexyloxy)benzene 6 was prepared. 4'-Benzyloxy 4-(2-hexenoxy)benzene $(4.7 \mathrm{~g}(17 \mathrm{mmol}))$ and $m$-chloroperoxybenzoic acid $(2.4 \mathrm{~g}(19 \mathrm{mmol}))$ were dissolved in benzene. The solution was stirred for $6 \mathrm{~h}$ and kept in a refrigerator for $24 \mathrm{~h}$. White precipitates were filtered, and successively washed with $10 \%$ sodium metabisulfite solu- tion, water, $5 \%$ sodium carbonate solution, and water. The compound was recrystallized from a mixture of ethyl acetate and hexane. yield of 6: $3.0 \mathrm{~g}(60 \%)$. In the third step, 4-(2,3-epoxyhexyloxy)phenol 4 was synthesized. The synthetic procedure was the same as that of 3. 4'-Benzyloxy 4-(2,3-epoxyhexyloxy)benzene $(3.0 \mathrm{~g}(10 \mathrm{mmol}))$ was reduced under hydrogen. The crude products were purified by column chromatography (silica gel; hexaneethyl acetate (5:5)), and recrystallized from a mixture of ethyl acetate and hexane. Yield of $4: 1.6 \mathrm{~g}(77 \%) \cdot \mathrm{mp} 56-58^{\circ} \mathrm{C}$.

\section{4-( $\omega$-Hydroxyalkyloxy)benzoic Acid}

4-( $\omega$-Hydroxyalkyloxy)benzoic acids having hexamethylene and undecamethylene groups were prepared according to the Ringsdorf's method. ${ }^{14} \mathrm{~A}$ representative synthesis is described for 4-( $\omega$-hydroxyhexyloxy)benzoic acid. 4-Hydroxybenzoic acid $(20.0 \mathrm{~g}(0.15 \mathrm{~mol}))$ was dissolved in a mixture of $60 \mathrm{ml}$ ethanol and a $55 \mathrm{ml}$ aqueous solution of $\mathrm{NaOH}(12.5 \mathrm{~g}$ $(0.31 \mathrm{~mol}))$. After heating the solution, a small amount of $\mathrm{KI}$ and $14.4 \mathrm{~g}(0.11 \mathrm{~mol})$ of 1-chlorohexanol were added. The mixture was refluxed for $20 \mathrm{~h}$. After cooling to room temperature, the solution was diluted with $200 \mathrm{ml}$ of $\mathrm{H}_{2} \mathrm{O}$ and acidified with dilute hydrogen chloride. White precipitates were filtered and washed with water. The products were recrystallized from ethanol. Yield: $18.8 \mathrm{~g}$ $(70 \%)$.

\section{4-( $\omega$-Acryloyloxyalkyloxy)benzoic Acid}

4-( $\omega$-Acryloyloxyalkyloxy)benzoic acid was prepared by esterification of 4- $(\omega$-hydroxyalkyloxy)benzoic acid with acrylic acid. 4-( $\omega$-Hydroxyhexyloxy)benzoic acid (16.0 g $(0.07 \mathrm{~mol}))$ was esterified with acrylic acid $(15.0 \mathrm{~g}(0.21 \mathrm{~mol}))$ in a Dean-Stark apparatus using $p$-toluenesulfonic acid $(8.0 \mathrm{~g})$ as catalyst and hydroquinone $(2.4 \mathrm{~g})$ as a radical inhibitor in benzene $(210 \mathrm{ml})$ at a refluxing temperature for $12 \mathrm{~h}$. After the reaction, the solution was diluted with diethyl ether and 
washed several times with hot water. The organic layer was separated and dried over megnesium sulfate: After evaporating the solution, the residue was recrystallized from a mixture of chloroform and hexane. Yield: $10.0 \mathrm{~g}(51 \%) . \mathrm{mp} 81-83^{\circ} \mathrm{C}$.

\section{Synthesis of Achiral Acrylic Monomers}

The synthetic procedure was the same as that of trans-EPAB-6. A representative procedure is described for 4'-(hexyloxy)phenyl 4-( $\omega$-acryloyloxyhexyloxy)benzoate. 4-( $\omega$-Acryloyloxyhexyloxy)benzoic acid $(2.6 \mathrm{~g}(8.9 \mathrm{mmol})$ was reacted with $4-(n$-hexyloxy)phenol $(1.7 \mathrm{~g}$ (8.9 mmol)). Yield: $1.6 \mathrm{~g}(38 \%)$. Anal. Calcd. for $\mathrm{C}_{28} \mathrm{H}_{36} \mathrm{O}_{6}$ : C, $71.77 \% ; \mathrm{H}, 7.74 \%$. Found: $\mathrm{C}, 71.23 \% ; \mathrm{H}, 7.86 \%$.

\section{Measurements}

NMR spectra were recorded with a JEOL GX-270 NMR spectrometer. For solid-state measurements, $\mathrm{CP} / \mathrm{MAS}{ }^{13} \mathrm{C} \mathrm{NMR}$ spectra were obtained with a bullet type Kel-F roter. Solution spectra were obtained in chloroform$d$ and dimethylsulfoxide- $d_{6}$ with tetramethylsilane as internal reference. Thermal analysis was carried out with a Perkin-Elmer DSC-2 calorimeter at a heating and cooling rate of $5^{\circ} \mathrm{C} / \mathrm{min}$ for monomers and $10^{\circ} \mathrm{C} / \mathrm{min}$ for polymers. The nature of the mesophase was examined using a polarizing microscope equipped with a Mettler EP80/84 hot stage. $\mathrm{X}$-Ray diffraction patterns were obtained using a Gaigerflex (Rigaku Denki Co.) diffractometer with $\mathrm{Cu}-K_{\alpha}$ radiation.

\section{Electron Beam (EB) Irradiation}

Electron beam irradiation was performed with a low-energy electrocurtain type accelerator (Nissin-High Voltage Co., Ltd.) under nitrogen. The acceleration voltage was $175 \mathrm{kV}$ and the irradiation dose was $2-20 \mathrm{Mrad}$. The sample film for EB irradiation was manufactured by the casting method in which the chloroform solution was cast on the polyethylene terephthalate film, dried and melted at $110^{\circ} \mathrm{C}$. Then, the obtained film was annealed at room temperature.

\section{RESULTS AND DISCUSSION}

The synthetic route and structure of monomers are exhibited in Scheme 1. First, an alkylene flexible spacer was introduced by etherfication to give 4-( $\omega$-hydroxyalkyloxy)benzoic acid. In the eq 2 , an acrylic double bond was introduced via an esterification to give 4-( $\omega$-acryloylalkyloxy)benzoic acid. In the next eq 3, 4-( $\omega$-acryloylalkyloxy)benzoic acid was coupled with $p$-substituted phenol, such as ethoxyphenol, $n$-hexyloxyphenol and 2,3-epoxyhexyloxyphenols. ${ }^{12}$ All monomers were characterized by elemental analysis, ${ }^{1} \mathrm{H}$ NMR, and ${ }^{13} \mathrm{C}$ NMR spectroscopy. The ${ }^{13} \mathrm{C}$ NMR spectra of trans-EPAB-6 are shown in Figure 1. The carbon absorption due to epoxy group was observed at 56.0 and $56.5 \mathrm{ppm}$. The synthetic route of substituted phenols having an epoxy group is shown in Schemes 2 and 3. The chiral epoxy (trans-epoxy) group was introduced by the Sharpless epoxydation ${ }^{13,14}$ as shown in Scheme 2. (E)-Hexenol as the starting material was treated with titanium tetraisopropoxide, (+)-tartaric acid diethyl ester, tert-butyl hydroperoxide, and molecular sieve $4 \mathrm{~A}$ in $\mathrm{CH}_{2} \mathrm{Cl}_{2}$. The specific rotation of the obtained epoxy compound was $-44.0^{\circ}$. An enantiomeric excess was determined by NMR to be $88 \%$. The obtained chiral epoxy compound, (S,S)-2,3-epoxyhexanol, was coupled with 4-benzyloxyphenol by Mitsunobu coupling, ${ }^{15}$ and debenzylation by reduction with hydrogen gave $p$-substituted phenols.

An achiral epoxy compound was obtained with a conventional epoxydation reagent such as $m$-chloroperoxybenzoic acid.

All monomers except EPAHB showed thermotropic liquid-crystalline. The chiral monomers demonstrated both the cholesteric phase with oily streak texture and the smectic phase. However, the chiral monomers did not show a chiral smectic C phase. DSC thermo- 


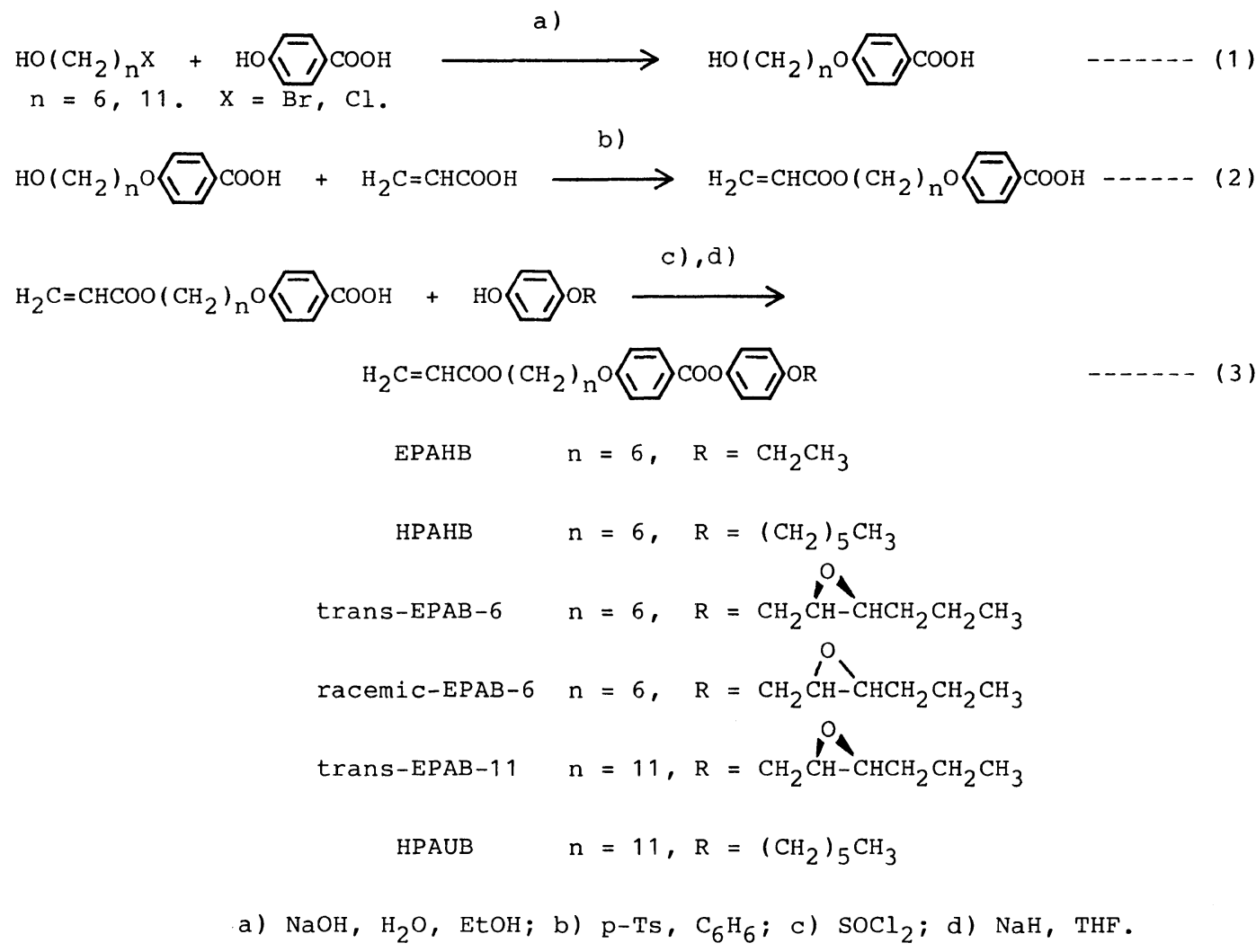

Scheme 1. Synthesis of 4 -(alkyloxy)phenyl 4-( $\omega$-acryloyloxyalkyloxy)benzoate.

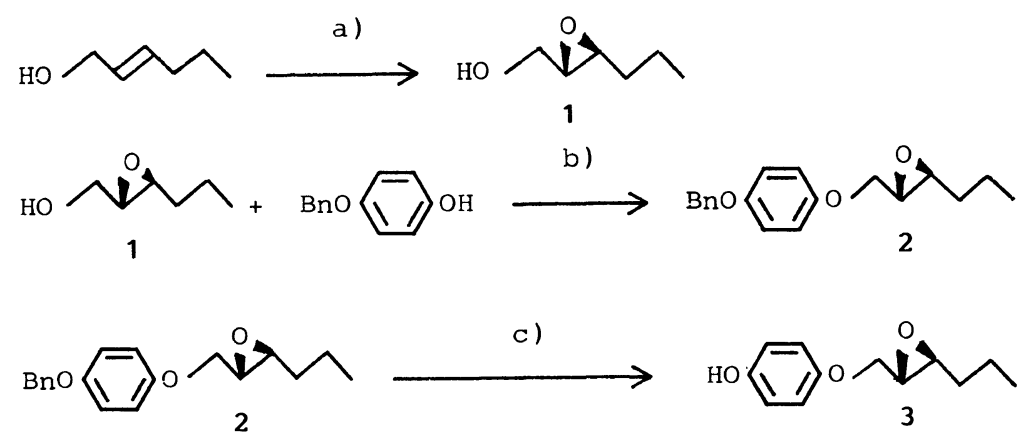
a) $\mathrm{Ti}(\mathrm{O}-\mathrm{iPr})_{4},(+)-\mathrm{DET}$, molecular sieve $4 \mathrm{~A}, \mathrm{CH}_{2} \mathrm{Cl}_{2}$;
b) Azodicarboxylic acid diethyl ester, $\mathrm{Ph}_{3} \mathrm{P}, \mathrm{THF}$;
c) $\mathrm{H}_{2}, \mathrm{Pd} / \mathrm{C}$, ethyl acetate.

Scheme 2. Synthesis of 4-[(S,S)-2,3-epoxyhexyloxy]phenol. 
$\mathrm{HO}+\mathrm{BnO}_{11} \mathrm{OH}$<smiles>CCC/C=C/COc1ccc(Br)cc1</smiles><smiles>CCCC1OC1COc1ccc(Br)cc1</smiles>

a)

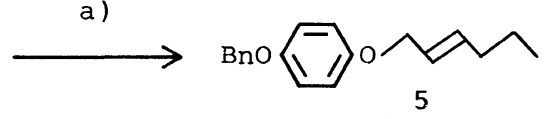

b)

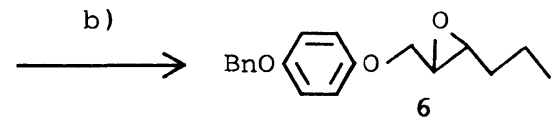

c)

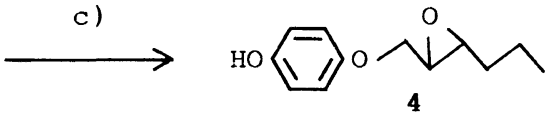

a) Azodicarboxylic acid diethyl ester, $\mathrm{Ph}_{3} \mathrm{P}, \mathrm{THF}$;

b) m-Chloroperoxybenzoic acid, $\mathrm{C}_{6} \mathrm{H}_{6}$,

c) $\mathrm{H}_{2}, \mathrm{Pd} / \mathrm{C}$, ethyl acetate.

Scheme 3. Synthesis of 4-(2,3-epoxyhexyloxy)phenol.
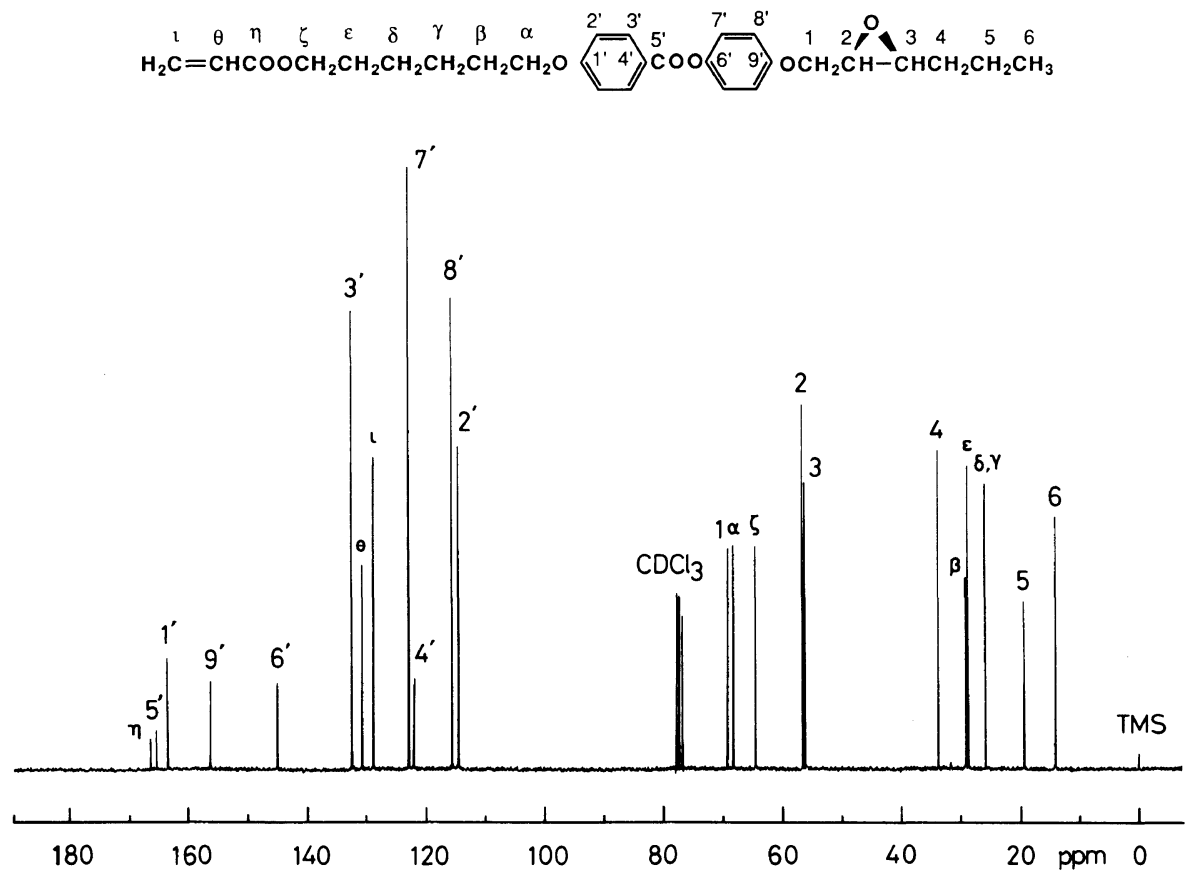

Figure 1. ${ }^{13} \mathrm{C}$ NMR spectra of $4^{\prime}-[(S, S)$-2,3-epoxyhexyloxy]phenyl 4-( $\omega$-acryloyloxyhexyloxy)benzoate (trans-EPAB-6) in chloroform- $d$.

grams of the chiral monomers, i.e., transEPAB-6 and trans-EPAB-11, are shown in Figure 2 in the 1 st cooling and the 2 nd heating. Thermal properties of the monomers are summarized in Table I. Each transition temperature, i.e., $T_{\mathrm{k}}$ (crystal-to-smectic), $T_{\mathrm{s}}$ (smectic-to-nematic, or smectic-to-cholesteric), and $T_{\mathrm{i}}$ (nematic-to-isotropic), of trans-EPAB-6 
Table I. Phase transition of acrylic monomers

\begin{tabular}{|c|c|c|c|}
\hline \multirow{2}{*}{ Material } & Phase transition ${ }^{\mathrm{a}}$ & LC range ${ }^{b}$ & Heat of fusion \\
\hline & ${ }^{\circ} \mathrm{C}$ & deg. & $\mathrm{kJ} \mathrm{mol}^{-1}$ \\
\hline ЕРАНВ & k $46 \mathrm{i}$ & - & k $28 \mathrm{i}$ \\
\hline НPAHB & k $26 \mathrm{~s} 55 \mathrm{n} 62 \mathrm{i}$ & 36 & $\mathrm{k} 17.1 \mathrm{~s} 2.4 \mathrm{n} 1.4 \mathrm{i}$ \\
\hline trans-EPAB-6 & k 19 s $56 \operatorname{ch} 71 \mathrm{i}$ & 52 & $\mathrm{k} 2.8 \mathrm{~s} 1.0 \mathrm{ch} 0.8 \mathrm{i}$ \\
\hline racemic-EPAB-6 & $\mathrm{k} 23 \mathrm{~s} 60 \mathrm{n} 75 \mathrm{i}$ & 52 & $\mathrm{k} 1.5 \mathrm{~s} 0.7 \mathrm{n} 1.2 \mathrm{i}$ \\
\hline trans-EPAB-11 & k $55 \mathrm{~s} 71 \mathrm{ch} 77 \mathrm{i}$ & 22 & $\mathrm{k} 4.1 \mathrm{~s} 1.6 \mathrm{ch} 1.4 \mathrm{i}$ \\
\hline HPAUB & k 21 s 44 n 66 i & 45 & k 22.5 s 5.2 n $2.1 \mathrm{i}$ \\
\hline
\end{tabular}

$\mathrm{k}$, crystalline; s, smectic; $\mathrm{n}$, nematic; ch, cholesteric; i, isotropic melt.

${ }^{a}$ Determined from DSC measurements of 1 st cooling at a scanning rate of $5 \mathrm{deg} \mathrm{min}^{-1}$ and cross-polarizing microscopy.

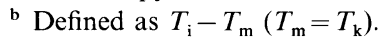

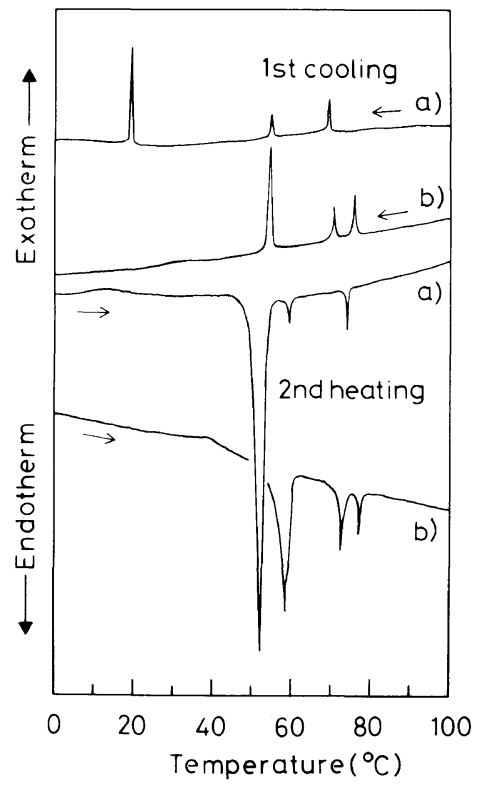

Figure 2. DSC thermograms in the 1st cooling and 2nd heating of acrylic monomers: a), trans-EPAB-6; b), trans-EPAB-11.

was by 4 degrees lower than that of the racemate. HPAHB having a hexamethylene spacer showed a liquid-crystalline range of 36 degrees, while the introduction of an epoxy group into the spacer led to broadening of the liquid-crystalline phase.

The enthalpy of the transition from nematic phase or isotropic phase to smectic A phase was usually about $4-6 \mathrm{~kJ} \mathrm{~mol}^{-1}$, indicating that these transitions were normally first order in nature. But, there were a few cases where the transition was quite small in enthalpy, which is considered to be second order in nature. Its was reported that the enthalpy value of the transition from nematic or smectic A to smectic $\mathrm{C}$ was extremely small, i.e., $<1 \mathrm{~kJ}$ $\mathrm{mol}^{-1} .^{16}$ For trans-EPAB-6, the enthalpy value from cholesteric to smectic phase was $1.0 \mathrm{~kJ} \mathrm{~mol}^{-1}$ and for trans-EPAB-11, it was $1.6 \mathrm{~kJ} \mathrm{~mol}^{-1}$. These values might indicate that the transition from cholesteric to smectic A phase is second order in nature. The enthalpy values of the crystal-to-smectic $\left(\Delta H_{\mathrm{k}-\mathrm{s}}\right)$ (appoximately $40 \mathrm{~kJ} \mathrm{~mol}^{-1}$ ) for both transEPAB-6 and trans-EPAB-1 1 in the 2 nd heating were consistent with the liquid-crystalline compound having mesogenic phenyl benzoate, which was reported in the literature. ${ }^{17}$

Six kinds of monomer films, prepared by annealing via nematic, cholesteric and smectic phases from the isotropic melt, were irradiated at 2 to $20 \mathrm{Mrad}$ by EB. After irradiation, the obtained polymers were purified by dissolution-reprecipitation three times using chloroform-methanol or by extraction with THF.

The results of polymerization are summarized in Table II. Although a non-liquidcrystalline monomer EPAHB gave soluble polymers in low yields, all the liquid-crystalline 
Solid-State Polymerization of Liquid-Crystalline Acrylic Monomers

Table II. EB-irradiated solid-state polymerization of acrylic monomers

\begin{tabular}{|c|c|c|c|c|c|c|}
\hline \multirow{2}{*}{ No. } & \multirow{2}{*}{ Monomer } & \multirow{2}{*}{$\frac{\text { Irradiation dose }}{\text { Mrad }}$} & \multicolumn{2}{|c|}{ Yield $/ \%$} & \multirow{2}{*}{$\begin{array}{c}\bar{M}_{n}^{\mathrm{a}} \\
\times 10^{-4}\end{array}$} & \multirow{2}{*}{$\begin{array}{c}\bar{M}_{w}{ }^{\mathrm{a}} \\
\times 10^{-4}\end{array}$} \\
\hline & & & Soluble polymer & Insoluble polymer & & \\
\hline 1 & ЕРАНB & 5 & trace & none & 0.8 & 1.5 \\
\hline 2 & & 10 & 3 & none & 1.5 & 4.8 \\
\hline 3 & & 15 & 16 & none & 2.4 & 7.2 \\
\hline 4 & & 20 & 20 & none & 1.8 & 5.2 \\
\hline 5 & HPAHB & 5 & 78 & none & 17 & 59 \\
\hline 6 & & 10 & 80 & none & 7.9 & 64 \\
\hline 7 & trans- & 2 & none & 11 & - & - \\
\hline 8 & (EPAB-6) & 5 & none & 40 & - & - \\
\hline 9 & & 10 & - & 90 & - & - \\
\hline 10 & & 15 & trace & 89 & - & - \\
\hline 11 & & 20 & trace & 82 & - & - \\
\hline 12 & racemic- & 5 & none & 91 & - & - \\
\hline 13 & (EPAB-6) & 10 & none & 86 & - & - \\
\hline 14 & & 15 & none & 86 & - & - \\
\hline 15 & & 20 & none & 84 & - & - \\
\hline 16 & trans- & 2 & none & 10 & - & - \\
\hline 17 & (EPAB-11) & 5 & none & 65 & - & - \\
\hline 18 & & 10 & trace & 75 & - & - \\
\hline 19 & & 15 & 5 & 74 & - & - \\
\hline 20 & & 20 & 10 & 75 & - & - \\
\hline 21 & HPAUB & 2 & 10 & none & 12 & 52 \\
\hline 22 & & 5 & 20 & none & 8.4 & 37 \\
\hline 23 & & 10 & 75 & none & 6.5 & 30 \\
\hline 24 & & 15 & 70 & 5 & 3.8 & 38 \\
\hline 25 & & 20 & 50 & 57 & 3.4 & 15 \\
\hline
\end{tabular}

a $\bar{M}_{n}$ and $\bar{M}_{w}$ were determined by GPC using THF as eluent based on standard polystyrene.

monomers provided high molecular weight polymers or insoluble polymers in high yields. Since the solid-state polymerization requires the presence of an intramolecular interaction, ${ }^{18}$ it is suggested that these liquid-crystalline monomers have a certain ordering in the solid-state structure which might be formed during annealing via the liquid-crystalline state from isotropic melt and that a close vicinity of acryloyl groups causes high polymerizability of the solid monomers. In addition, all the polymers obtained from monomers containing an epoxy group were insoluble, crosslinked polymers.

The introduction of an epoxy group in the acrylic monomer was done to obtain a liquid-crystalline polymer with a chiral group. However, the epoxy group seems to take part in the crosslinking, giving a crosslinked polymer by EB polymerization. Previously, we reported that in the EB polymerization of acrylic monomer-polymer system, a graft polymer was prepared by the formation of a radical at the carbonyl group of poly(alkyl acrylate) ${ }^{4}$

The thermal properties of the polymers except for poly(EPAHB) obtained at $5 \mathrm{Mrad}$ irradiation, were examined by DSC. Poly(EPAHB) was obtained at $20 \mathrm{Mrad}$. The DSC thermograms are shown in Figure 3. Poly(trans-EPAB-6), which is an insoluble, crosslinked polymer, showed three endothermic 


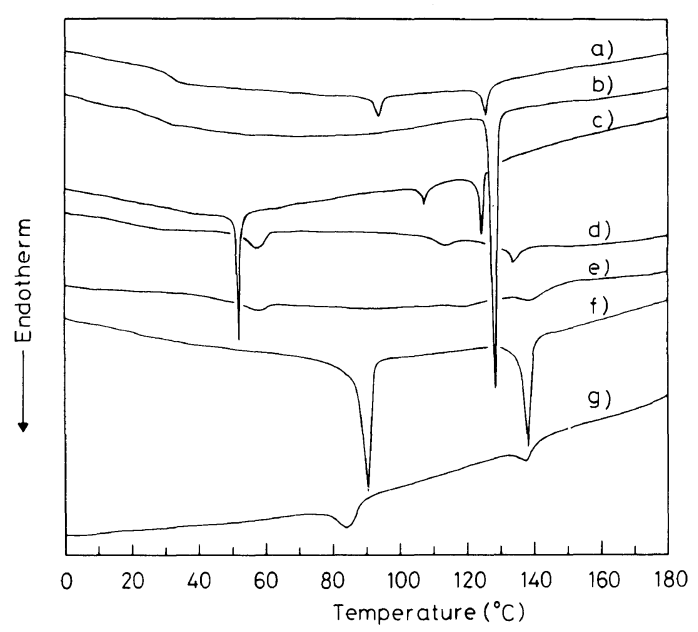

Figure 3. DSC thermograms in the 2nd heating of EB-irradiated polymers and radical polymerized polymer. a), poly(EPAHB) (No. 4); b), poly(HPAHB) (No. 5); c), radical polymerized soluble poly(trans-EPAB-6); d), poly(trans-EPAB-6) (No. 8); e), poly(racemic-EPAB-6) (No. 12); f), poly(trans-EPAB-11) (No. 17); g), poly(HPAUB) (No. 22). Heating rate, $10 \mathrm{deg} \mathrm{min}^{-1}$.

peaks. Thus, the thermal behavior of this crosslinked polymer was compared with that of a soluble poly(trans-EPAB-6) prepared by polymerizing trans-EPAB-6 with azobisisobutyronitrile as initiator in toluene. The latter polymer also exhibited three endothermic peaks in the DSC thermograms (Figure 3(c)). The microscopic observation of the soluble polymer revealed that the three peaks were assignable to crystal-to-smectic $\left(T_{\mathrm{m}}\right)$, smecticto-nematic $\left(T_{\mathrm{s}-\mathrm{n}}\right)$, and nematic-to-isotropic $\left(T_{\mathrm{i}}\right)$ transitions. But, for soluble polymers, the nematic phase could not be distinguished from the cholesteric phase. The DSC thermograms of the soluble poly(trans-EPAB-6) showed $T_{\mathrm{m}}$ of $52^{\circ} \mathrm{C}, T_{\mathrm{s}-\mathrm{n}}$ of $107^{\circ} \mathrm{C}$, and $T_{\mathrm{i}}$ of $124^{\circ} \mathrm{C}$. Accordingly, it was concluded that for the crosslinked poly(trans-EPAB-6), the three peaks were due to the above transitions. For the crosslinked poly(trans-EPAB-6) obtained at $5 \mathrm{Mrad}$ irradiation, these values were $58^{\circ} \mathrm{C}$, $117^{\circ} \mathrm{C}$, and $133^{\circ} \mathrm{C}$, respectively. The heat of fusion $(\Delta H)$ of the soluble poly(trans-EPAB-6) was $1.1 \mathrm{calg}^{-1}$ and that of crosslinked
poly(trans-EPAB-6), $0.7 \mathrm{cal} \mathrm{g}^{-1}$. Such differences in $T_{\mathrm{m}}$ and $\Delta H$ indicate that the epoxy group in the side chain seems to take part in the crosslinking reaction during EB polymerization.

In the DSC thermograms of poly(racemicEPAB-6) which is a crosslinked polymer, the endothermic peaks were not so sharp as those of crosslinked poly(trans-EPAB-6). On the other hand, a crosslinked poly (trans-EPAB-11) with an undecamethylene spacer exhibited two endothermic peaks corresponding to $T_{\mathrm{m}}$ and $T_{\mathrm{i}}$.

In Figure 4, for EB-polymerized and radically-polymerized poly(trans-EPAB-11)s, solid-state CP/MAS ${ }^{13} \mathrm{C}$ NMR spectra are shown as well as a solution spectrum of the latter polymer. The peak assignment was carried out according to the literature. ${ }^{19,20}$ Comparing the spectrum (C) for the crosslinked, EB-polymerized polymer with the spectrum (B) for the soluble polymer, there was little difference between both solid-state spectra, though the former spectrum exhibited high noise level. Thus, it was suggested that the crosslinking might be caused by a small degree of scission of the epoxy group which was not detectable by NMR spectroscopy or by a reaction caused by an activated epoxy group. It is noteworthy that the epoxy ring was not opened by a conventional radical initiator such as AIBN.

To examine molecular orientation and crystallinity of crosslinked polymers, X-ray diffraction was measured (Figure 5). All polymers examined, i.e., poly(trans-EPAB-6), poly(racemic-EPAB-6), and poly(trans-EPAB11), exhibited a rather broad reflection at $2 \theta=20^{\circ}$ corresponding to the lateral ordering of the phenyl benzoate mesogen. The degree of crystallinity increased in the order of poly(racemic-EPAB-6) (No. 12), poly(transEPAB-6) (No. 8), and poly(trans-EPAB-11) (No. 17). For the three polymers, the degree of crystallinity was estimated to be $15 \%, 22 \%$, and $44 \%$, respectively. 


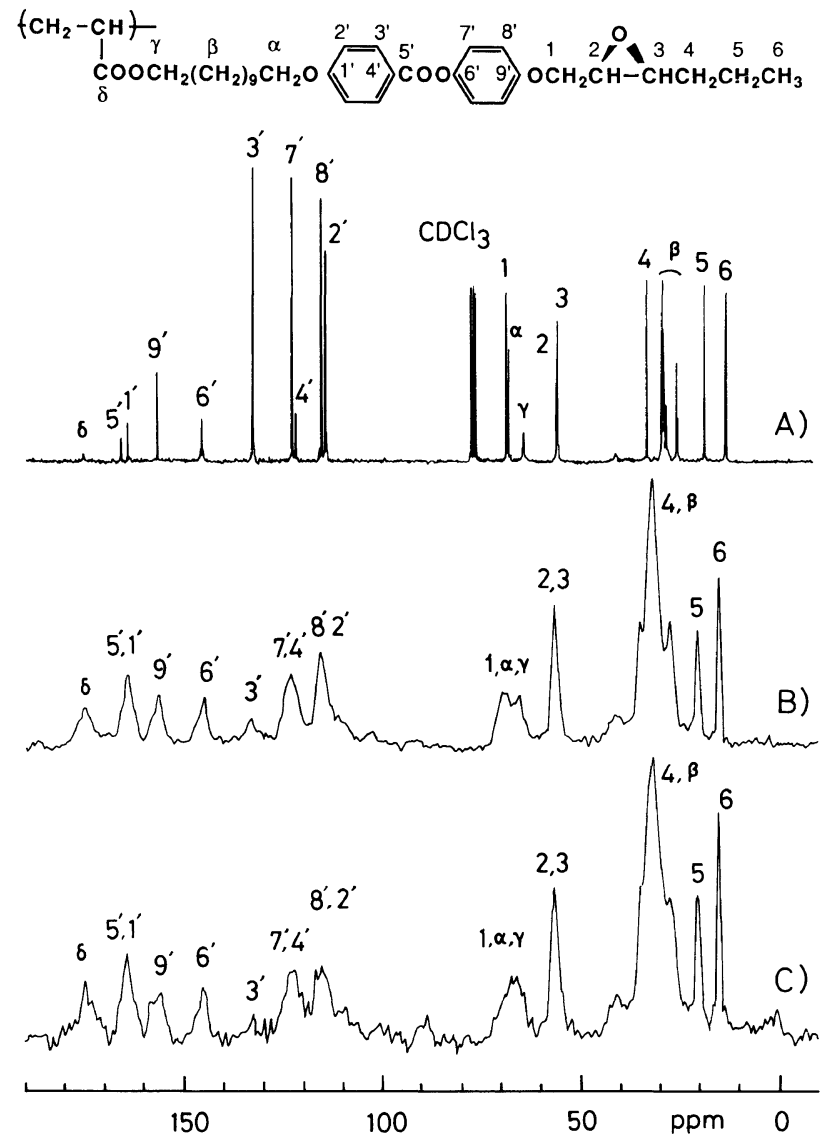

Figure 4. $67.8 \mathrm{MHz}$ solid-state $\mathrm{CP} / \mathrm{MAS}$ spectra of poly(trans-EPAB-11). (A), solution spectrum in chloroform- $d$; (B), radical polymerization reaction by AIBN as initiator; (C), solid-state polymerization by EB at 10 Mrad.

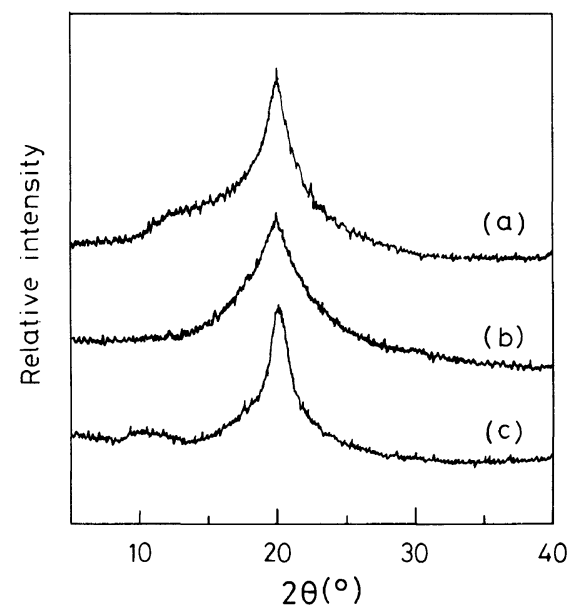

Figure 5. X-Ray diffraction patterns of EB-cured polymers. a), poly(trans-EPAB-6) (No. 8); b), poly(racemicEPAB-6) (No. 12); c), poly(trans-EPAB-11) (No. 17).

\section{REFERENCES}

1. T. M. Santosucco, Radiat. Phys. Chem., 25, 557 (1985).

2. L. H. Wadahwa and W. K. Walsh, J. Appl. Polym. Sci., 27, 591 (1982).

3. W. Oraby and W. K. Walsh, J. Appl. Polym. Sci., 23, 3227 (1979).

4. R. Takiguchi and T. Uryu, J. Appl. Polym. Sci., 30, 709 (1985).

5. R. Takiguchi and T. Uryu, J. Appl. Polym. Sci., 31, 2083 (1986).

6. A. Griffin, C. Hall, C. Hoyle, K. Venataram, and C. McArdle, Makromol. Chem. Rapid. Commun., 9, 463 (1988).

7. C. B. McArdle, "Side Chain Liquid Crystal Polymers," Chapman and Hall, New York, 1989.

8. S. Esselin, L. Bosio, C. Noel, G. Decobert, and J. C. Bubois, Liquid Crystals, 2, 505 (1987). 
9. V. P. Shivaev, S. G. Kostromin, N. A. Plate, S. A. Ivanov, V. Yu. Vetrov, and I. A. Yakovlev, Polym. Commun., 24, 364 (1983).

10. M. Ando and T. Uryu, J. Appl. Polym. Sci., 33, 1973 (1987).

11. M. Ando and T. Uryu, Kobunshi Ronbunshu, 46, 285 (1989).

12. M. Portugall, H. Ringsdorf and R. Zental, Makromol. Chem., 183, 2311 (1982).

13. J. G. Hill and K. B. Sharpless, Org. Synth., 63, 66 (1984).

14. Y. Gao, R. M. Hanson, J. M. Klunder, S. Y. Ko., H. Masamune, and K. B. Sharpless, J. Am. Chem.
Soc., 109, 5765 (1987).

15. O. Mitsunobu, Synthesis, 1 (1981).

16. G. Gray and J. W. Goodby, "Smectic Liquid Crystals," Heydon \& Son Inc., Philadelphia, 1984.

17. S. M. Kelly, R. Buchecker, and M. Schadt, Liquid Crystals, 3, 1115 (1988).

18. F. L. Hirshfeld and G. M. Schmidt, J. Polym. Sci., A2, 2181 (1964).

19. C.-D. Poon, J. Afzal, M. Gangoda, and B. M. Fung, Mag. Res. Chem., 24, 1014 (1986).

20. T. Uryu and T. Kato, Macromolecules, 21, 378 (1988). 